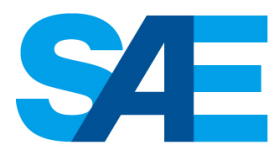

\title{
A Statistical Characterization of School Bus Drive Cycles Collected via Onboard Logging Systems
}

\author{
Adam Duran and Kevin Walkowicz \\ National Renewable Energy Laboratory
}

\begin{abstract}
In an effort to characterize the dynamics typical of school bus operation, National Renewable Energy Laboratory (NREL) researchers set out to gather in-use duty cycle data from school bus fleets operating across the country. Employing a combination of Isaac Instruments GPS/CAN data loggers in conjunction with existing onboard telemetric systems resulted in the capture of operating information for more than 200 individual vehicles in three geographically unique domestic locations. In total, over 1,500 individual operational route shifts from Washington, New York, and Colorado were collected.

Upon completing the collection of in-use field data using either NREL-installed data acquisition devices or existing onboard telemetry systems, large-scale duty-cycle statistical analyses were performed to examine underlying vehicle dynamics trends within the data and to explore vehicle operation variations between fleet locations. Based on the results of these analyses, high, low, and average vehicle dynamics requirements were determined, resulting in the selection of representative standard chassis dynamometer test cycles for each condition.

In this paper, the methodology and accompanying results of the large-scale duty-cycle statistical analysis are presented, including graphical and tabular representations of a number of relationships between key duty-cycle metrics observed within the larger data set. In addition to presenting the results of this analysis, conclusions are drawn and presented regarding potential applications of advanced vehicle technology as it relates specifically to school buses.
\end{abstract}

CITATION: Duran, A. and Walkowicz, K., "A Statistical Characterization of School Bus Drive Cycles Collected via Onboard Logging Systems," SAE Int. J. Commer. Veh. 6(2):2013, doi:10.4271/2013-01-2400.

\section{INTRODUCTION}

Understanding vehicle usage plays a fundamental role in assessing the performance potential of new vehicle technologies, leading to more informed decision making, better test procedures $[\underline{1}, \underline{2}, \underline{3}, \underline{4}, \underline{5}, \underline{6}, \underline{7}]$, more commercially successful designs, and lowered manufacturing and operating expenses. Of the methods available for modeling vehicle usage, operational drive/duty cycles have shown the ability to accurately represent vehicle operating information in an efficient and streamlined manner well suited to downstream analysis $[\underline{8}, \underline{9}, \underline{10}, \underline{11}, \underline{12}, \underline{13}, \underline{14}, \underline{15}, \underline{16}, \underline{17}]$. Typically consisting of speed and time information, these seemingly simple pieces of information, when properly understood, have been used to assess the value of new technology and to aid in corresponding development and deployment.
In an effort to better understand the operating characteristics of school buses across the country and examine the dynamics challenges associated with the school bus vocation, National Renewable Energy Laboratory (NREL) researchers, with the cooperation of local school districts and Zonar Systems, collected drive cycle information on class 6 and 7 school buses operating in three unique geographic locations. The class 6 and 7 school buses, with typical capacities of 71 to 84 passengers, were located in the states of Washington, New York, and Colorado. Although smaller-sized vehicles exist that fall under the vocational category of school buses, no data was collected or examined associated with this special subset, as vehicles falling within this group display operating characteristics dissimilar to their larger counterparts. 
Upon completion of the data collection phase of this study, detailed drive cycle analysis were performed to characterize typical school bus operating behavior. Examining a number of metrics associated with vehicle energy consumption and driving behavior, statistical relationships between key metrics of interest were explored, and representative standard chassis dynamometer test cycles were chosen corresponding to high, average, and low driving aggressiveness.

\section{APPROACH}

\section{Data Collection and Drive Cycle Analysis}

Drive cycles used to model vehicle operation are composed of corresponding vehicle speed vs. time points. To capture the in-use drive cycle information analyzed as part of this study and to attempt to characterize the operation of school buses across the country, NREL researchers instrumented school buses located in three unique geographic regions (Colorado, Washington, New York) with onboard mounted Isaac Instruments DRU 900 and DRU 908 data loggers configured to collect $1-\mathrm{Hz}$ global positioning system (GPS) data. The data sampling rate of $1 \mathrm{~Hz}$ was chosen based on the results of previous studies $[\underline{1}, \underline{2}, \underline{3}, \underline{4}, \underline{6}, \underline{7}]$. In addition to the deployment of manually installed devices, data were also collected using preinstalled Zonar Systems telemetric GPS devices at the same 1-Hz sampling rate. Employing both systems, data from a total of 1,718 route shifts reflecting the operation of 212 vehicles were captured over a period of several weeks. An example of the Isaac Instruments data loggers employed as part of this study is shown in Figure 1.

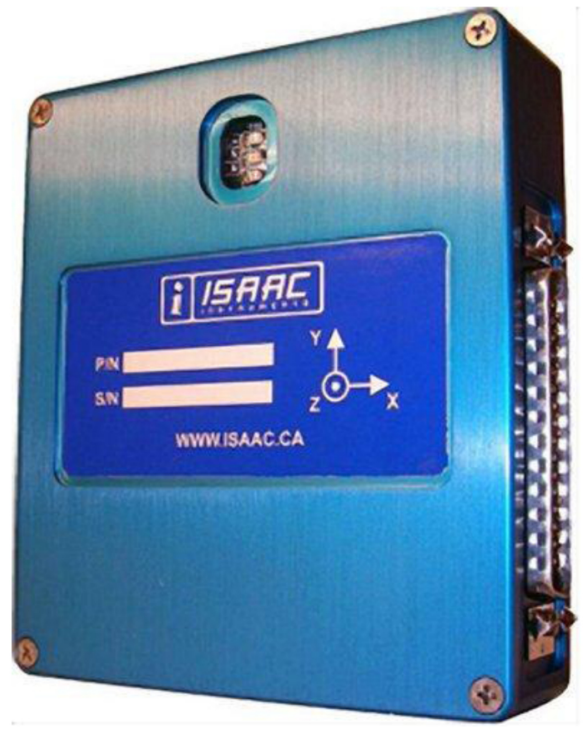

Figure 1. Isaac Industries data logging device

Of the 1,718 route shift data collected as part of this study, 814 cycles were collected from source vehicles operating in Colorado, 874 from buses in Washington, and the 30 remaining from vehicles in New York. The distribution of source vehicles similarly paralleled the drive cycle distribution by geographic region. Of the 212 vehicles from which data were collected, 102 of these vehicles were located in Colorado, 107 in Washington, and 3 in New York. Both the Colorado and Washington locations included large numbers of vehicles with preinstalled telemetric GPS data logging devices, allowing for large-scale data acquisition, while the vehicles examined in New York required manual instrument installation, resulting in limited-scale deployment of data logging devices.

Once the $1-\mathrm{Hz}$ drive cycles had been captured, the raw field data stored on the data acquisition devices were downloaded onto a local computer for post processing and analysis. The raw drive cycles were filtered and analyzed using NREL's Drive Cycle Rapid Investigation, Visualization, and Evaluation tool (DRIVE) [1ㅇ, 19] to generate individual drive cycle summary statistics. Using NREL's DRIVE tool, each drive cycle collected was characterized according to a total of 172 unique metrics, including key metrics such as operating speed distribution, stops per mile, acceleration rate, and vehicle kinetic intensity, a measure of the energy consumption nature of a cycle [ 6 ]. The analytical procedure performed as part of the DRIVE software was repeated using batch processing techniques, generating group-level statistics through the aggregation of individual drive cycles. Depending on how the data were aggregated into groups, researchers were able to examine statistical trends and relationships on multiple scales, ranging from the small-scale individual vehicle level, to geographic grouping, and finally to large-scale aggregation. As this study was concerned with characterizing overall school bus operation, the results presented herein reflect the analysis performed on the global conglomeration of experimental data.

\section{Representative Test Cycle Selection}

Once the data collection and preliminary drive cycle analysis had been completed, standard chassis dynamometer test cycles were chosen that reflected high, average, and low operating aggressiveness. For this particular study, the terms high, average, and low aggressiveness reflect the nature of energy consumption of the cycle, with the highly aggressive cycle representative of energy consumption primarily through stop-and-go driving behavior associated with urban driving conditions, and the low aggressive cycle representative of energy consumption through aerodynamic drag consistent with high-speed cruising associated with highway driving. As energy consumption was the key focus of cycle selection, the test cycles chosen as part of this study were selected using a multivariate least squares approach. The metrics kinetic intensity, stops per mile, and standard deviation of speed are examples of the primary selection parameters. To visualize the multivariate selection approach, a simplified single variable ranking example can be observed in Figure 2. 


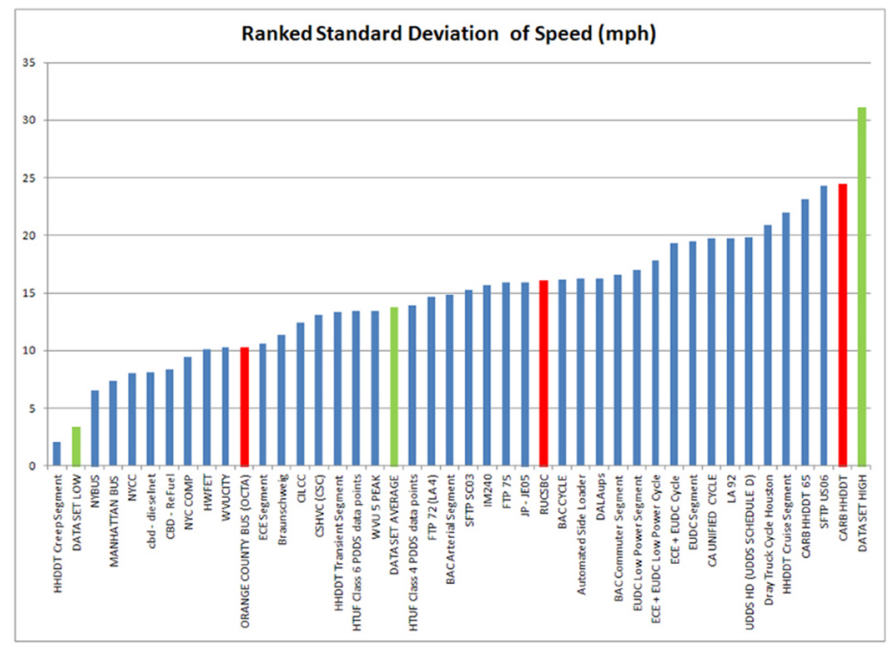

Figure 2. Example single metric ranking distribution

\section{RESULTS}

\section{Operating Duration, Distance, and Driving} Speed Distribution

Analyzing the aggregated results of the drive cycle analysis performed on the school bus data, one observes normality in the distribution of route duration data. Examining the distribution in Figure 3, it is shown that the average operational shift is 2.63 hours in duration, with a minimum duration of 0.14 hour and a maximum observed duration of 7.94 hours. Calculating the standard deviation in route duration, we find sigma to be 1.14 hours. Employing standard confidence interval assumptions based on normally distributed data and combining the observed average route duration with the calculated set standard deviation, the $99.7 \%$ confidence interval for route duration was found to be zero to 6.04 hours. While the route duration statistics may appear small in comparison to other vocations, it is important to note that typical daily school bus operation consists of two route shifts, which when examined on a daily level would result in the doubling of the duration values mentioned previously. Taking into account dual shifts associated with daily behavior, the average school bus is typically in operation for 5.26 hours out of a standard 8-hour work day. This difference in operating time may allow for potential inter-shift charging opportunities should battery electric or plug-in hybrid electric vehicle technology be implemented in future school bus design.
Similar to the distribution of the route duration metric, the driving distances calculated as part of the drive cycle analysis performed on the aggregate data set revealed strong normality, as shown in Figure 4. Of the over 1,500 individual operating shifts analyzed as part of this study, the average driving distance observed was 31.73 miles, with a maximum observed driving distance of 127.36 miles and a minimum distance of 1.45 miles. Calculating the set standard deviation, sigma was found to be 15.17 miles. Again assuming normality based on the driving distance distribution, a $99.7 \%$ confidence interval on route distance was determined and found to be zero to 77.23 miles. Similarly to route duration, doubling the route distance to reflect daily operating distances, it is found that on average school buses travel 73.46 miles, with a $99.7 \%$ cutoff on driving distance of 154.46 miles. Given the relatively low mileage average route mileage requirements, there is significant potential for hybridization or electrification as energy storage requirements can be minimized to take advantage of the limited range requirements and potential for inter-shift charging.

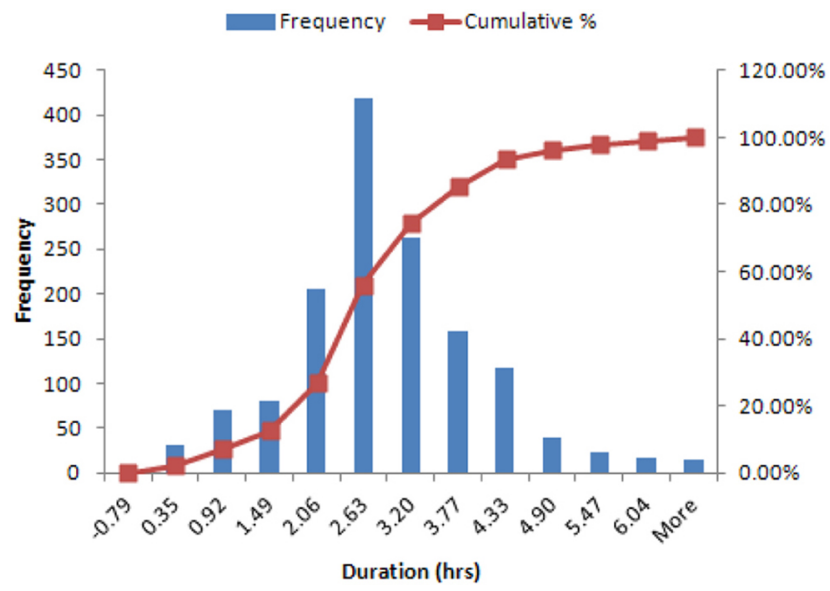

Figure 3. Route duration - 3-sigma distribution

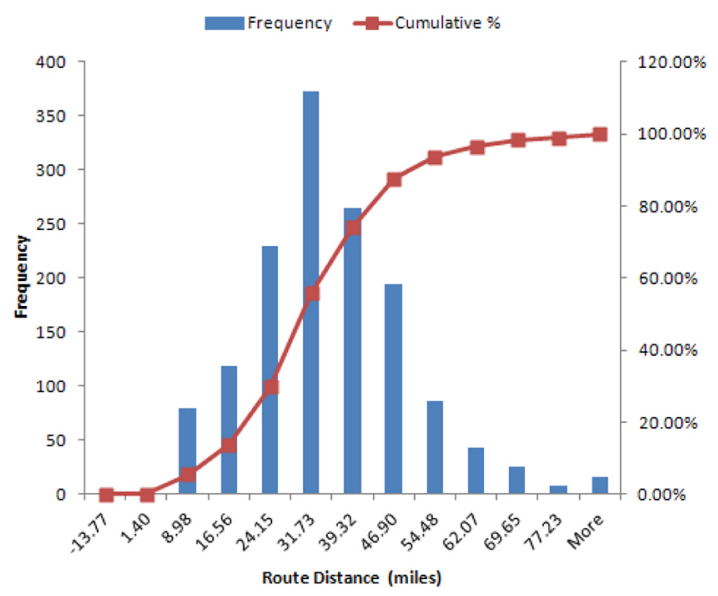

Figure 4. Route distance - 3-sigma distribution 
Having examined both route distance and duration in great detail, another set of global metrics of interest in characterizing overall vehicle information are the distribution of vehicle operating speed. Collecting and tabulating the operating speed information for each of the collected drive cycles, one observes zero speed operation as the primary speed occurring during vehicle operation. As shown in Table $1,53.25 \%$ of operating time is spent at zero speed, with approximately $98 \%$ of vehicle operation occurring at speeds below $50 \mathrm{mph}$. Given this speed distribution, we conclude that the vehicles examined rarely achieve highway speeds as part of their typical route operation. Additionally, since a significant portion of the drive cycle time is spent at idle, there is significant opportunity for fuel consumption savings via idle reduction technology or electrification/hybridization. Removing fuel consumed while the vehicle is stationary has the potential to result in a significant increase in vehicle fuel economy.

Table 1. Observed Speed Distribution

\begin{tabular}{|c|c|c|}
\hline Speed Bin & Data Set Average & Data Set STD \\
\hline $\begin{array}{c}\text { zero speed time } \\
(\%)\end{array}$ & 53.25 & 13.38 \\
\hline $\begin{array}{c}0+-5 \text { mph time } \\
(\%)\end{array}$ & 3.59 & 1.32 \\
\hline $\begin{array}{c}\begin{array}{c}5+-10 \mathrm{mph} \text { time } \\
(\%)\end{array} \\
\end{array}$ & 5.25 & 1.90 \\
\hline $\begin{array}{c}10+-15 \text { mph time } \\
(\%)\end{array}$ & 5.83 & 2.07 \\
\hline $\begin{array}{c}15+-20 \mathrm{mph} \text { time } \\
(\%)\end{array}$ & 5.76 & 2.37 \\
\hline $\begin{array}{c}20+-25 \text { mph time } \\
(\%)\end{array}$ & 6.11 & 2.66 \\
\hline $\begin{array}{c}25+-30 \text { mph time } \\
(\%)\end{array}$ & 5.83 & 2.82 \\
\hline $\begin{array}{c}30+-35 \text { mph time } \\
(\%)\end{array}$ & 5.22 & 2.45 \\
\hline $\begin{array}{c}35+-40 \text { mph time } \\
(\%)\end{array}$ & 3.96 & 2.24 \\
\hline $\begin{array}{c}40+-45 \text { mph time } \\
(\%)\end{array}$ & 2.52 & 2.10 \\
\hline $\begin{array}{c}45+-50 \mathrm{mph} \text { time } \\
(\%)\end{array}$ & 1.11 & 1.40 \\
\hline $\begin{array}{c}50+-55 \text { mph time } \\
(\%)\end{array}$ & 0.59 & 1.27 \\
\hline $\begin{array}{c}55+-60 \text { mph time } \\
\text { (\%) }\end{array}$ & 0.53 & 1.29 \\
\hline $\begin{array}{c}60+-65 \text { mph time } \\
(\%)\end{array}$ & 0.32 & 1.01 \\
\hline $\begin{array}{c}65+-70 \text { mph time } \\
(\%)\end{array}$ & 0.11 & 0.74 \\
\hline $\begin{array}{c}70+-75 \mathrm{mph} \text { time } \\
(\%)\end{array}$ & 0.03 & 0.47 \\
\hline $\begin{array}{c}75+\underset{(\%)}{\text { mph time }} \\
(\%)\end{array}$ & 0.00 & 0.11 \\
\hline
\end{tabular}

\section{Route Kinematics Characterization}

In addition to characterizing the route on a distance and duration level, route kinematics were also characterized as part of the drive cycle analysis. Table 2 shows the distribution and confidence intervals associated with a number of key metrics associated with route kinematics. $\underline{\text { Figures } 5}, \underline{6}, \underline{7}, \underline{8}$ confirm the normality of the distributions of a subset of these metrics. Examining the metrics contained in Table 2, one can draw a number of conclusions. First, the mean maximum driving speed observed in the collection of drive cycles matches the speed distribution determined previously. With a mean maximum speed of $54.48 \mathrm{mph}$, it can be confirmed that the majority of vehicle operation occurs at speeds below $55 \mathrm{mph}$. In addition, examining the mean average driving speed and mean standard deviation of speed, we find that school buses operate along low speed routes with high amounts of speed variation. However, much of this variation may be attributed to the stop frequency of the vehicle. Examining both the stops-per-mile and stops-perminute metrics, it is found that, as one would expect, school buses make frequent stops on both distance traveled and time scales. Combining high frequency of stops with a similarly high standard deviation of speed, we observe a mean kinetic intensity of 1.63 which is indicative of more energy consumption over the cycle being attributable to vehicle acceleration than to aerodynamic losses. As the school bus drive cycle contains a high number of stops per mile and operates at a low average driving speed, there is energy saving potential in the recapture of braking energy and reduction in vehicle launch energy requirements.

Table 2. Key Route Drive Cycle Kinematic Metrics Summary

\begin{tabular}{|c|c|c|c|c|c|}
\hline Metric & Minimum & Mean & Maximum & STD & $\mathbf{9 9 . 7 \% ~ C I ~}$ \\
\hline $\begin{array}{c}\text { Max Driving Speed } \\
(\mathrm{mph})\end{array}$ & 31.94 & 54.48 & 79.50 & 8.85 & $27.92: 81.03$ \\
\hline $\begin{array}{c}\text { Average Driving } \\
\text { Speed } \\
(\mathrm{mph})\end{array}$ & 13.50 & 23.31 & 53.77 & 4.15 & $10.85: 35.77$ \\
\hline $\begin{array}{c}\text { Standard Deviation } \\
\text { of Speed } \\
(\mathrm{mph})\end{array}$ & 3.36 & 13.73 & 31.13 & 2.97 & $4.83: 22.64$ \\
\hline $\begin{array}{c}\text { Stops per Mile } \\
\text { Stops per Minute }\end{array}$ & 0.20 & 1.73 & 6.14 & 0.61 & $0.0: 3.54$ \\
\hline $\begin{array}{c}\text { Average Acceleration } \\
\left(\mathrm{ft} / \mathrm{s}^{2}\right)\end{array}$ & 0.78 & 1.57 & 2.32 & 0.21 & $0.95: 2.20$ \\
\hline $\begin{array}{c}\text { Average Deceleration } \\
\left(\mathrm{ft} / \mathrm{s}^{2}\right)\end{array}$ & -0.78 & -1.67 & -2.32 & 0.22 & $-2.32:-1.02$ \\
\hline $\begin{array}{c}\text { Characteristic } \\
\text { Acceleration [6] } \\
\left(\mathrm{ft} / \mathrm{s}^{2}\right)\end{array}$ & 0.25 & 0.63 & 1.04 & 0.10 & $0.33: 0.93$ \\
\hline $\begin{array}{c}\text { Aerodynamic Speed } \\
{[6]} \\
(\mathrm{ft} / \mathrm{s})\end{array}$ & 30.90 & 47.64 & 95.67 & 8.83 & $22.49: 72.78$ \\
\hline $\begin{array}{c}\text { Kinetic Intensity [6] } \\
(1 / \mathrm{mile})\end{array}$ & 0.16 & 1.63 & 5.57 & 0.66 & $0: 3.62$ \\
\hline
\end{tabular}




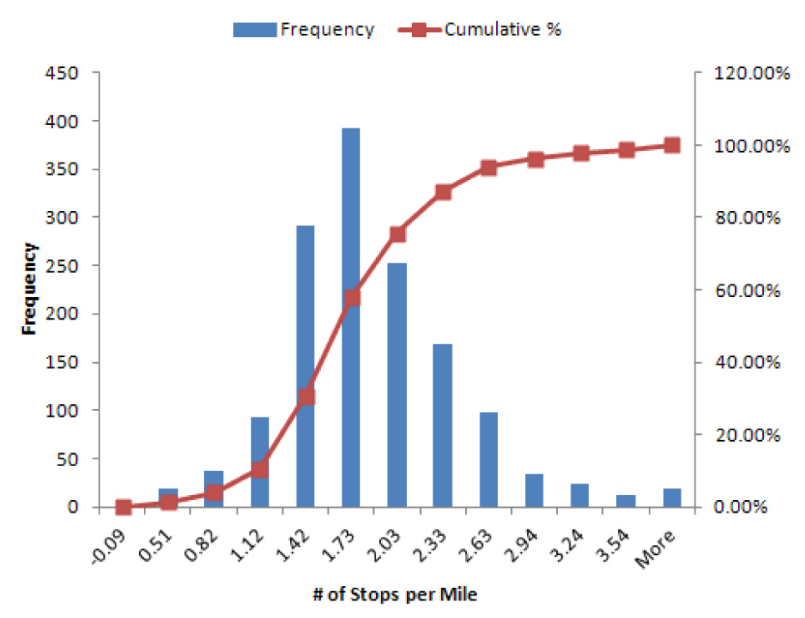

Figure 5. Stops per mile - 3-sigma distribution

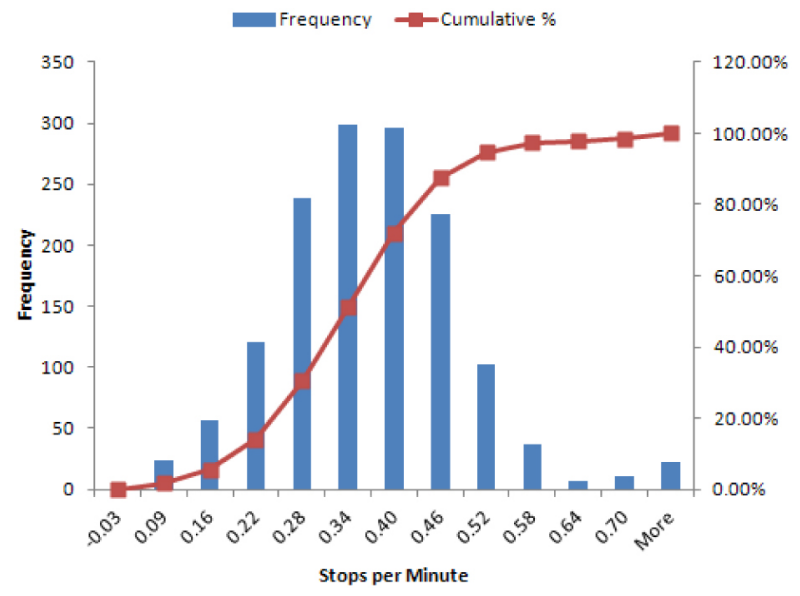

Figure 6. Stops per minute - 3-sigma distribution

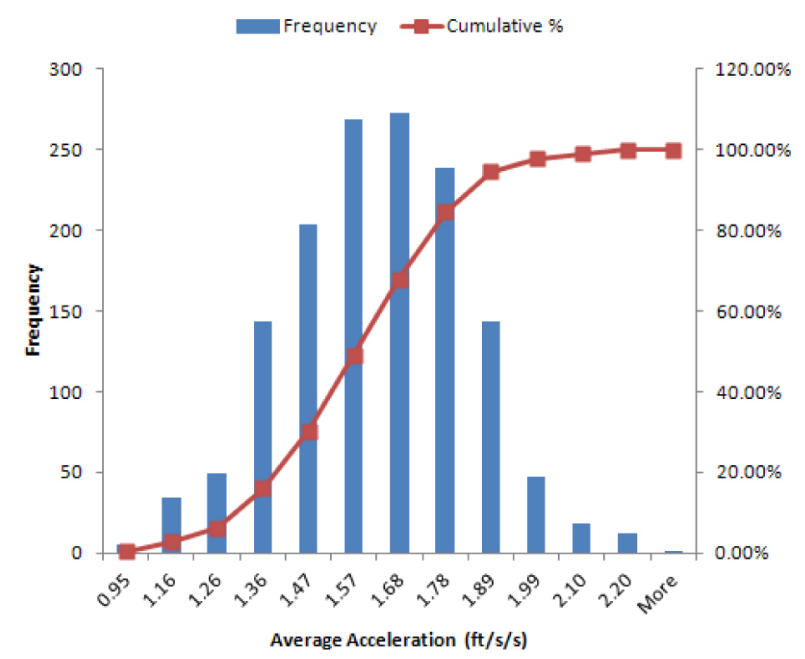

Figure 7. Average acceleration - 3-sigma distribution

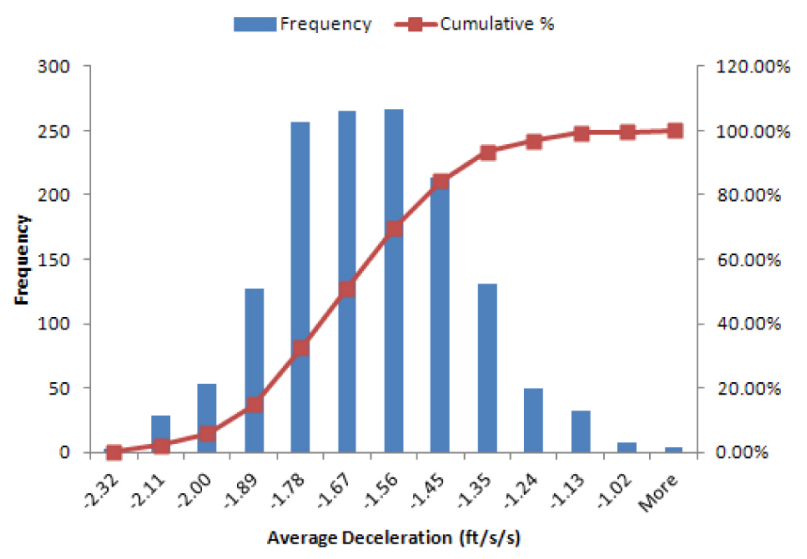

Figure 8. Average deceleration - 3-sigma distribution

\section{Bivariate Route Analysis}

Building upon the univariate analysis performed to examine global kinematics and route information; additional bivariate analyses were performed on the drive cycle data set to investigate the influence of geography on key metrics. In addition to exploring the influence of geography on vehicle operation, the bivariate analyses were performed to study any potential relationships between variables. Examining the variables in Table 2, only a handful displayed any level of correlation, including average driving speed, kinetic intensity, and stops per mile.

Examining the correlation between average driving speed and kinetic intensity, one observes a strong power correlation between the two variables. Evaluating the Pearson correlation coefficient for the power fit of the data $\left(\mathrm{R}^{2}=0.7533\right)$, the presence of a statistically significant relationship can be confirmed to the $10^{-7}$ order. Even more interesting than the presence of a strong power relationship, is the clustering of data by geographic region. We see in Figure 9 that the data collected from Colorado had a higher average driving speed and lower corresponding kinetic intensity than either the data sets collected from Washington or New York. This could be associated with potentially less-congested driving conditions or the presence of higher speed limits in the area.

When average driving speed is examined with respect to the number of stops per mile, as in Figure 10, another power correlation is observed. Once again evaluating the Pearson correlation coefficient for the power fit of the data $\left(\mathrm{R}^{2}=\right.$ 0.6338), we observe the relationship between stops per mile and average driving speed to be statistically significant to the $10^{-7}$ order. Once again, similar to the previous relationship, we see that geography plays a significant role in the location of data along the power curve. New York in particular exhibits a higher number of stops per mile than the other two geographic regions examined, while displaying a lower average driving speed. Based on this relationship we can conclude that average driving speed is influenced by the number of stops per mile, with routes possessing large 
numbers of stops per miles also possessing a low overall average driving speed. This conclusion also agrees with the relationship presented in Figure 9, as the greater number of stops per mile would result in greater energy consumption occurring due to acceleration from a stopped state.

Finally, examining the relationship between the number of stops per mile and kinetic intensity of the cycle revealed another interesting relationship within the data set. Examining the aggregated data set shown in Figure 11, it appears as though there is a linear relationship between the number of stops per mile on a specific route and its corresponding kinetic intensity. However, what is of greater interest in this case is the influence of geography on the linear relationship. It appears as though both Colorado and New York follow a similar linear trend, while the Washington data display a slightly different linear behavior.

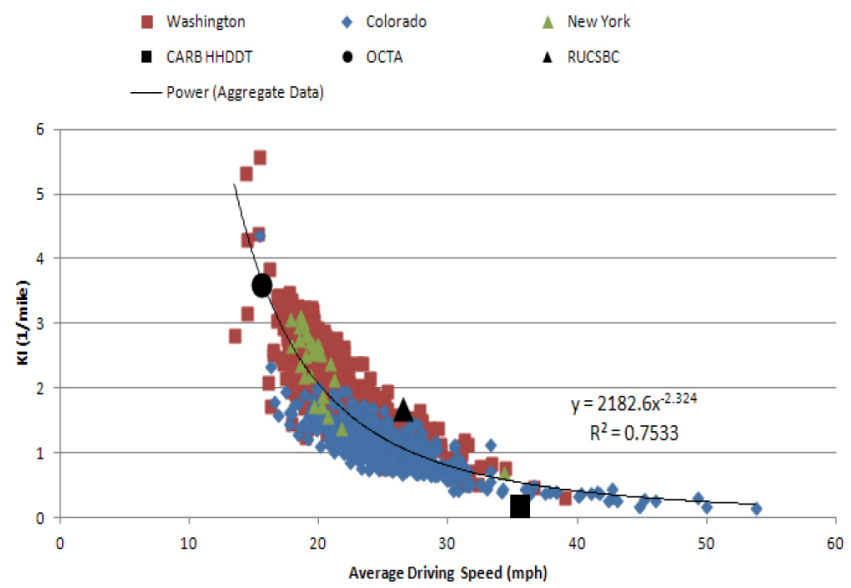

Figure 9. Route drive-cycle level comparison of average driving speed to kinetic intensity

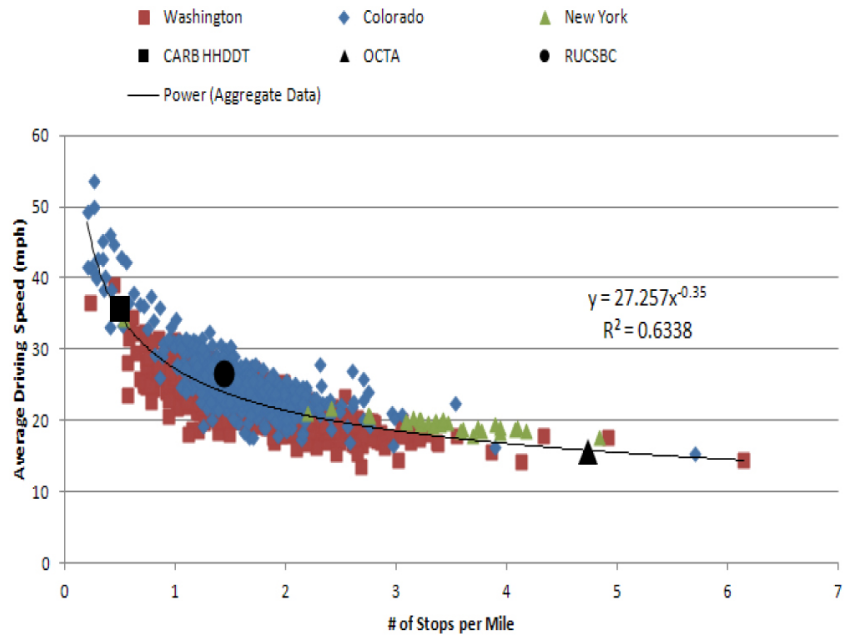

Figure 10. Route drive cycle level comparison of stops per mile to average driving speed

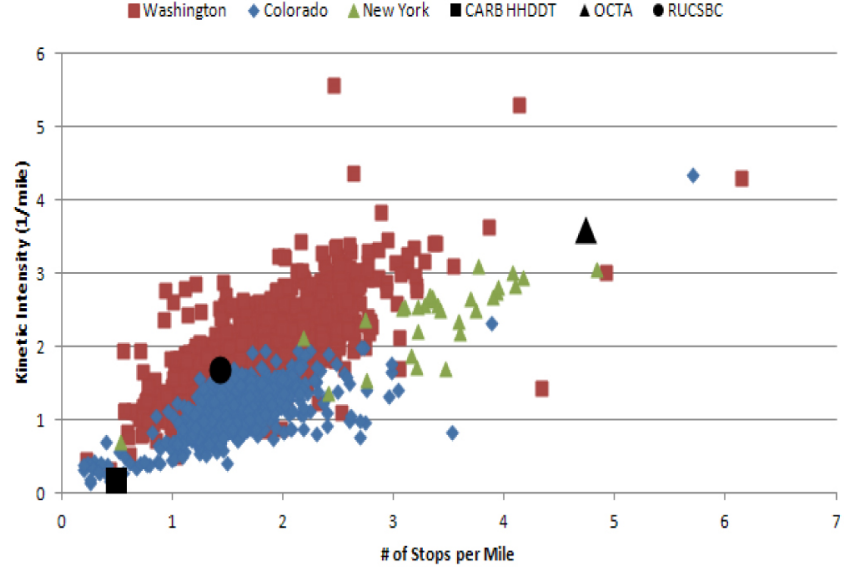

Figure 11. Route drive cycle level comparison of stops per mile to kinetic intensity

\section{Representative Test Cycle Selection}

Completing the drive cycle analysis, representative test cycles were selected using a multivariate least squares method. Table 3 shows the three standard chassis test cycles chosen as well as the values of a number of the key metrics used as part of the selection process. The cycles are listed in order from most aggressive (OCTA) to least aggressive (HHDDT) as defined previously.

\section{Table 3. Representative Cycle Selection Results}

\begin{tabular}{|c|c|c|c|c|c|c|}
\hline Metric & OCTA & RUCSBC & CARB HHDDT & Minimum & Mean & Maximum \\
\hline $\begin{array}{c}\text { Max Driving Speed } \\
(\mathrm{mph})\end{array}$ & 40.63 & 49.70 & 59.3 & 31.94 & 54.48 & 79.50 \\
\hline $\begin{array}{c}\text { Average Driving Speed } \\
(\mathrm{mph})\end{array}$ & 15.67 & 26.59 & 35.59 & 13.50 & 23.31 & 53.77 \\
\hline $\begin{array}{c}\text { Standard Deviation of Speed } \\
(\mathrm{mph})\end{array}$ & 10.30 & 16.05 & 24.48 & 3.36 & 13.73 & 31.13 \\
\hline Stops per Mile & 4.74 & 1.44 & 0.50 & 0.20 & 1.73 & 6.14 \\
\hline $\begin{array}{c}\text { Characteristic Acceleration } \\
\left(\mathrm{ft} / \mathrm{s}^{2}\right)\end{array}$ & 0.714 & 0.86 & 0.18 & 0.25 & 0.63 & 1.04 \\
\hline $\begin{array}{c}\text { Aerodynamic Speed } \\
(\mathrm{ft} / \mathrm{s})\end{array}$ & 32.41 & 51.88 & 74.36 & 30.90 & 47.64 & 95.67 \\
\hline $\begin{array}{c}\text { Kinetic Intensity } \\
\left(1 / \mathrm{mile}^{2}\right)\end{array}$ & 3.59 & 1.68 & 0.17 & 0.16 & 1.63 & 5.57 \\
\hline
\end{tabular}

Examining the metrics for the cycles chosen, we see that the low-aggression cycle displays high-speed highway driving behavior, while the high-aggression cycle reflects lower-speed city driving. These differences are also highlighted in the difference in stops per miles between the cycles as well as their kinetic intensity.

\section{CONCLUSION}

Based on the results of the duty cycle analysis performed on the school bus fleet data, is has been shown that a number of interesting relationships appear as part of the underlying vehicle operation. Strong exponential relationships exist between a number of significant operating metrics, including average driving speed, stops per mile, and kinetic intensity. In addition, basic results correlating the influence of geography on route behavior have been observed. It may be of interest to explore further efforts to greater examination of the effect 
geography plays on vehicle operation, specifically in the area of operational duty cycle.

In addition to observing interesting relationships between duty cycle metrics and geographic influences, it is worthwhile to note the significant idle time occurs as part of typical school bus operation. Due to the large amount of time spent at zero speed as part of daily route operation, it may be of interest to investigate additional idle reduction technologies or charging strategies in the case of hybrid electric vehicle applications.

\section{REFERENCES}

1. Ivanič, Ž., "Data Collection and Development of New York City Refuse Truck Duty Cycle," SAE Technical Paper 2007-01-4118, 2007, doi: $10.4271 / 2007-01-4118$

2. Dembski, N., Rizzoni, G., Soliman, A., Fravert, J. et al., "Development of Refuse Vehicle Driving and Duty Cycles," SAE Technical Paper 2005-01-1165, 2005, doi:10.4271/2005-01-1165.

3. Hearne, J., Toback, A., Akers, J., Hesketh, R. et al., "Development of a New Composite School Bus Test Cycle and the Effect of Fuel Type on Mobile Emissions from Three School Buses," SAE Technical Paper 2005-01-1616, 2005, doi:10.4271/2005-01-1616,

4. Kulkarni, A., Sapre, R., and Sonchal, C., "GPS Based Methodology for Drive Cycle Determination," SAE Technical Paper 2005-01-1060, 2005, doi: $10.4271 / 2005-01-1060$.

5. Casey, E., Smith, W., and Timoney, D., "Examination of Low-cost Systems for the Determination of Kinematic Driving Cycles and Engine Operating Conditions in Dublin, Ireland," SAE Technical Paper 2009-01-2791, 2009, doi:10.4271/2009-01-2791.

6. O'Keefe, M., Simpson, A., Kelly, K., and Pedersen, D., "Duty Cycle Characterization and Evaluation Towards Heavy Hybrid Vehicle Applications," SAE Technical Paper 2007-01-0302, 2007, doi: $10.4271 / 2007-01-0302$

7. Barnitt, R. and Gonder, J., "Drive Cycle Analysis, Measurement of Emissions and Fuel Consumption of a PHEV School Bus," SAE Technical Paper 2011-01-0863, 2011, doi:10.4271/2011-01-0863.

8. Frey, H.C., et al. "In-Use Measurement of the Activity, Energy Use, and Emissions of a Plug-in Hybrid Electric Vehicle," Paper 2009-A-242AWMA, Proceedings, 102nd Annual Conference and Exhibition, Air \& Waste Management Association, Detroit, Michigan, June 16-19 2009.

9. Earleywine, M., et al. "Simulated Fuel Economy and Performance of Advanced Hybrid Electric and Plug-In Hybrid Electric Vehicles Using In-Use Travel Profiles." Vehicle Power and Propulsion Conference (VPPC), 2010 IEEE, pp. 1-6, 1-3 September 2010.

10. Gonder, J., et al. "Using Global Positioning System Travel Data to Assess Real-World Energy Use of Plug-In Hybrid Electric Vehicles." Transportation Research Record: Journal of the Transportation Research Board, volume 2017, pp. 26-32, 2007.

11. Kwon, J., Kim, J., Fallas, E., Pagerit, S. et al., "Impact of Drive Cycles on PHEV Component Requirements," SAE Technical Paper 2008-01-1337, 2008, doi: 10.4271/2008-01-1337.

12. Sharer, P., Leydier, R., and Rousseau, A., "Impact of Drive Cycle Aggressiveness and Speed on HEVs Fuel Consumption Sensitivity," SAE Technical Paper 2007-01-0281, 2007, doi:10.4271/2007-01-0281.

13. Johansson, K. and Alvfors, P., "The Effect of Drive Cycles on the Performance of a PEM Fuel Cell System for Automotive Applications," SAE Technical Paper 2001-01-3454, 2001, doi:10.4271/2001-01-3454.

14. Smith, K., Earleywine, M., Wood, E., Neubauer, J. et al., "Comparison of Plug-In Hybrid Electric Vehicle Battery Life Across Geographies and Drive Cycles," SAE Technical Paper 2012-01-0666, 2012, doi: $10.4271 / 2012-01-0666$

15. Kulkarni, N., Jadhav, N., and Nandkeolyar, K., "Drive Cycle for Commercial Vehicles for Selection of Power Train to Get Optimum Fuel Efficiency," SAE Technical Paper 2009-01-2886, 2009, doi: $10.4271 / 2009-01-2886$

16. Carlson, R., Lohse-Busch, H., Duoba, M., and Shidore, N., "Drive Cycle Fuel Consumption Variability of Plug-In Hybrid Electric Vehicles Due to Aggressive Driving," SAE Technical Paper 2009-01-1335, 2009, doi: 10.4271/2009-01-1335.

17. Fellah, M., Singh, G., Rousseau, A., Pagerit, S. et al., "Impact of RealWorld Drive Cycles on PHEV Battery Requirements," SAE Technical Paper 2009-01-1383, 2009, doi:10.4271/2009-01-1383.

18. Duran, A. and Earleywine, M., "GPS Data Filtration Method for Drive Cycle Analysis Applications," SAE Technical Paper 2012-01-0743, 2012, doi:10.4271/2012-01-0743.

19. NREL Vehicle Drive Cycle Tool, User Guide. Copyright (C) 2009 Alliance for Sustainable Energy, LLC. All Rights Reserved.

\section{CONTACT INFORMATION}

Adam Duran is a research engineer working with the Transportation and Hydrogen Systems Center at the National Renewable Energy Laboratory. Adam's work focuses primarily in the areas of drive cycle analysis and characterization, custom drive cycle development, and medium/heavy-duty fleet evaluations. He may be reached at Adam.Duran@nrel.gov.

Kevin Walkowicz is the Team Leader for Fleet Testing and Evaluation at the National Renewable Energy Laboratory in Golden, $\mathrm{CO}$ and one of the principal investigators for the U.S. Department of Energy's Advanced Vehicle Testing Activity. His primary focus is on capturing, analyzing and reporting in-use data related to electric drive medium- and heavy-duty vehicles. $\mathrm{He}$ can be reached at Kevin.Walkowicz@nrel.gov.

\section{ACKNOWLEDGMENTS}

The authors wish to thank Lee Slezak, U.S. Department of Energy Vehicle Technologies Office, as well as the U.S. Department of Energy for its support in conducting this project. In addition, the authors would like to acknowledge Zonar Systems for their assistance in the procurement of telemetric data examined as part of this study.

\section{DEFINITIONS/ABBREVIATIONS}

CARB HHDDT - California Air Resources Board Heavy Heavy-Duty Diesel Truck Cycle

DRIVE - Drive Cycle Rapid Investigation, Visualization, and Evaluation tool

EV - electric vehicle

GPS - global positioning system

HEV - hybrid electric vehicle

mph - mile per hour

NREL - National Renewable Energy Laboratory

OCTA - Orange County Transit Authority Bus Cycle. Also known as Orange County Bus Cycle.

RUCSBC - Rowan University Composite School Bus Cycle s - second 